Article

\title{
Comparative Physiological and Biochemical Changes in Tomato (Solanum lycopersicum L.) under Salt Stress and Recovery: Role of Antioxidant Defense and Glyoxalase Systems
}

\author{
Khursheda Parvin ${ }^{1}$, Mirza Hasanuzzaman ${ }^{2, *}$, M. H. M. Borhannuddin Bhuyan ${ }^{1}(\mathbb{0}$, \\ Kamrun Nahar ${ }^{3}$, Sayed Mohammad Mohsin ${ }^{1}$ and Masayuki Fujita ${ }^{1, *}$ \\ 1 Laboratory of Plant Stress Responses, Department of Applied Biological Sciences, Faculty of Agriculture, \\ Kagawa University, Miki-Cho, Kita-Gun, Kagawa 761-0795, Japan \\ 2 Department of Agronomy, Sher-e-Bangla Agricultural University, Sher-e-Bangla Nagar, \\ Dhaka 1207, Bangladesh \\ 3 Department of Agricultural Botany, Sher-e-Bangla Agricultural University, Sher-e-Bangla Nagar, \\ Dhaka 1207, Bangladesh \\ * Correspondence: mhzsauag@yahoo.com (M.H.); fujita@ag.kagawa-u.ac.jp (M.F.); \\ Tel.: +880-1716587711 (M.H.); +81-87898-3033 (M.F.)
}

Received: 30 June 2019; Accepted: 27 August 2019; Published: 1 September 2019

\begin{abstract}
Salinity toxicity and the post-stress restorative process were examined to identify the salt tolerance mechanism in tomato, with a focus on the antioxidant defense and glyoxalase systems. Hydroponically grown 15 day-old tomato plants (Solanum lycopersicum L. cv. Pusa Ruby) were treated with 150 and $250 \mathrm{mM} \mathrm{NaCl}$ for 4 days and subsequently grown in nutrient solution for a further 2 days to observe the post-stress responses. Under saline conditions, plants showed osmotic stress responses that included low leaf relative water content and high proline content. Salinity induced oxidative stress by the over-accumulation of reactive oxygen species $\left(\mathrm{H}_{2} \mathrm{O}_{2}\right.$ and $\left.\mathrm{O}_{2}{ }^{\bullet-}\right)$ and methylglyoxal. Salinity also impaired the non-enzymatic and enzymatic components of the antioxidant defense system. On the other hand, excessive $\mathrm{Na}^{+}$uptake induced ionic stress which resulted in a lower content of other minerals $\left(\mathrm{K}^{+}, \mathrm{Ca}^{2+}\right.$, and $\left.\mathrm{Mg}^{2+}\right)$, and a reduction in photosynthetic pigment synthesis and plant growth. After 2 days in the normal nutrient solution, the plants showed improvements in antioxidant and glyoxalase system activities, followed by improvements in plant growth, water balance, and chlorophyll synthesis. The antioxidant and glyoxalase systems worked in concert to scavenge toxic reactive oxygen species (ROS), thereby reducing lipid peroxidation and membrane damage. Taken together, these findings indicate that tomato plants can tolerate salinity and show rapid post-stress recovery by enhancement of their antioxidant defense and glyoxalase systems.
\end{abstract}

Keywords: antioxidant defense; methylglyoxal; oxidative stress; post stress restoration; reactive oxygen species

\section{Introduction}

Salinity is an abiotic stress factor that drastically hinders plant growth and productivity by altering plant cellular homeostasis, physiology, metabolism, and biochemistry through the imposition of osmotic and ionic stress [1]. The first effect of a high concentration of salt in a plant is osmotic stress. Under this condition, the plant undergoes osmotic adjustment, reduces cell expansion and cell division, induces stomatal closure, and decreases its leaf area, thereby suppressing photosynthesis and growth [2]. Plants under salt stress accumulate high amounts of sodium ion $\left(\mathrm{Na}^{+}\right)$and leak large 
quantities of potassium ion $\left(\mathrm{K}^{+}\right)$from their cells through enhanced $\mathrm{Na}^{+} / \mathrm{K}^{+}$exchange, which leads to ionic stress [2]. Besides, high $\mathrm{Na}^{+}$uptake causes chlorosis and necrosis of mature leaves, along with premature senescence, through disruption of protein synthesis and enzyme activity $[2,3]$.

Under natural conditions, a plant responds and adapts to salinity through alterations in cellular metabolism and defense mechanisms [1,3,4]. Different abiotic stresses, including salinity, enhance the production of reactive oxygen species (ROS), such as singlet oxygen $\left({ }^{1} \mathrm{O}_{2}\right)$, superoxide $\left(\mathrm{O}_{2}{ }^{\bullet-}\right)$ anion, hydrogen peroxide $\left(\mathrm{H}_{2} \mathrm{O}_{2}\right)$, and hydroxyl radical $\left(\mathrm{OH}^{\bullet}\right)$, thereby inducing oxidative stress $[5,6]$. Oxidative stress damages the components of cellular organelles, such as lipids, nucleic acids, and proteins, which in turn disrupts normal cell metabolism and membrane functions, while triggering lipid peroxidation and, ultimately, programmed cell death [7]. Thus, control of ROS production is essential not only to prevent injurious ROS effects but also to ensure proper execution of their signaling functions [8].

Plants have developed several defense mechanisms, as well as signaling actions, to regulate both the formation and the removal of ROS to avoid oxidative damage [8,9]. The antioxidant defense system efficiently scavenges excess ROS by the coordinated action of different enzymes, that include superoxide dismutase (SOD), catalase (CAT), ascorbate peroxidase (APX), monodehydroascorbate reductase (MDHAR), dehydroascorbate reductase (DHAR), glutathione reductase (GR), glutathione peroxidase (GPX), and glutathione $S$-transferase (GST), as well as by the involvement of multiple non-enzymatic reactions $[6,10]$.

One less well-studied compound with the ability to generate ROS and oxidative stress in plants is methylglyoxal (MG), another cytotoxic and highly reactive compound. However, plants have a glyoxalase system, consisting of the glyoxalase I (Gly I) and glyoxalase II (Gly II) enzymes that, together with glutathione (GSH), detoxify MG into nontoxic compounds [5]. This raises the possibility that an efficient concomitant regulation of the antioxidant defense and glyoxalase systems may be important in conferring salt tolerance in plants.

Salt stress has detrimental effects on plants, but the plant response during the post-stress period is also very critical for recovery from stress-induced damage and subsequent survival. As in the stress condition, plants also show responsive behaviors when the stress is relieved that allow recovery from salt-induced injury. One previous report has described the restoration of growth in salt-stressed plants upon removal of the stress [11]. Other reports have indicated a reduction in oxidative damage and toxic ion accumulations [12]. However, information is lacking regarding the physiological responses and the involvement of the antioxidant and glyoxalase systems after the withdrawal of salt stress. This gap in knowledge prompted the present study, which focused on the plant physiological attributes, as well as the activities of the antioxidant defense and glyoxalase systems, during a post-stress period to obtain a better understanding of the mechanisms that underlie the recovery of plants from salt stress.

\section{Materials and Methods}

\subsection{Plant Materials and Stress Treatments}

Uniform and healthy tomato (Solanum lycopersicum L. cv. Pusa Ruby) seeds were surface sterilized with $70 \%$ ethanol (5 min). Fifteen seeds were placed on two layers of moistened filter paper in Petri plates and incubated in a germination chamber. After $5 \mathrm{~d}$, the number of plants per plate was reduced to 10 healthy plants and the plates were transferred to a growth chamber. The plants were supplied with full strength Hoagland nutrient solution [13] and grown under controlled conditions (light: $350 \mu \mathrm{mol}$ photon $\mathrm{m}^{-1} \mathrm{~s}^{-2}$, photoperiod: $16 / 8 \mathrm{~h}$ of light/dark, temperature: $25 \pm 2{ }^{\circ} \mathrm{C}$, and relative humidity: $65-70 \%$ ) for the next $10 \mathrm{~d}$. Several trials were conducted prior to the actual experiment to determine the highest salt level exposure with the shortest recovery period. We found that tomato plants recovered within $48 \mathrm{~h}$ from the damage induced by $250 \mathrm{mM} \mathrm{NaCl}$. Therefore, we selected 150 and $250 \mathrm{mM} \mathrm{NaCl}$ and $96 \mathrm{~h}$ as the stress conditions and a subsequent $48 \mathrm{~h}$ in normal nutrient solution for the recovery condition to investigate the recovery mechanism. After $96 \mathrm{~h}$ of salt stress, the plants 
were moved to the recovery solution by removing the salt solution, washing the plants with distilled water, and then supplying the nutrient solution. The third and fourth leaves of the tomato plants were analyzed after both the stress and recovery phases. The whole experiment was conducted three times and included three replications per treatment, with 10 plants per replication. Morphological data were obtained as the averaged values from 10 randomly selected plants.

\subsection{Determination of Growth Parameters}

Plant height, root length, number of leaves, and stem girth were recorded. The shoots, leaves, and roots were removed and weighed to determine fresh weights and were then dried at $80^{\circ} \mathrm{C}$ for $48 \mathrm{~h}$ to obtain dry weights.

\subsection{Determination of Na and Other Mineral Nutrients}

Sodium, $\mathrm{K}, \mathrm{Ca}$, and $\mathrm{Mg}$ content in the plant shoots and roots were determined from oven dried material $\left(72 \mathrm{~h} ; 70{ }^{\circ} \mathrm{C}\right)$ digested with an acid mixture $\left(\mathrm{HNO}_{3}: \mathrm{HClO}_{4} ; 5: 1, v / v\right)$ at $70{ }^{\circ} \mathrm{C}$ for $48 \mathrm{~h}$ [2]. The mineral contents were analyzed by atomic absorption spectrophotometry (AA-7000 instrument, Shimadzu, Japan).

\subsection{Measurement of Photosynthetic Pigment Contents}

Leaf chlorophyll $a(\mathrm{Chl} a)$, chlorophyll $b(\mathrm{Chl} b)$, and carotenoid (Car) contents were measured according to Wellburn [14] using absolute ethanol.

\subsection{Measurement of Relative Water and Free Proline Content in Leaves}

Relative water content (RWC) was determined from fully developed leaves following the protocol of Barrs and Weatherley [15]. The fresh weight (FW) of 10 leaves was measured, the leaves were then immersed in distilled water, and turgid weight (TW) was obtained $8 \mathrm{~h}$ later. Dry weight (DW) was measured after drying the leaf samples at $80^{\circ} \mathrm{C}$ for $48 \mathrm{~h}$. The RWC was calculated using following equation:

$$
\operatorname{RWC}(\%)=(\mathrm{FW}-\mathrm{DW}) /(\mathrm{TW}-\mathrm{DW}) \times 100
$$

Free proline (Pro) content in the leaf tissue was determined according to Bates et al. [16] using acid ninhydrin prepared with glacial acetic acid and phosphoric acid. The ninhydrin-Pro complex was extracted with toluene.

\subsection{Evaluation of Oxidative Stress Markers}

Lipid peroxidation was measured as the malondialdehyde (MDA) content based on the production of thiobarbituric acid reactive substances (TBARS) [17]. The $\mathrm{H}_{2} \mathrm{O}_{2}$ levels were measured according to Hossain et al. [18] using potassium iodide (KI).

Increased generation of $\mathrm{H}_{2} \mathrm{O}_{2}$ and $\mathrm{O}_{2}{ }^{\bullet-}$ in tomato leaves was histochemically confirmed using 3,3-diaminobenzidine (DAB) and nitrobluetetrazolium (NBT), respectively [19].

Electrolyte leakage (EL) from leaf and root tissues was estimated following the protocol of Dionisio-Sese and Tobita [20].

\subsection{Protein Quantification and Enzyme Activity Assays}

Fresh leaf tissue (0.5 g) was homogenized and extracted according to Hasanuzzaman et al. [21], which was then used to analyze protein content and the enzyme activity assay.

The protein content was determined according to Bradford [22] using bovine serum albumin as a protein standard.

Lipoxygenase (LOX; EC: 1.13.11.12) activity was determined following Doderer et al. [23]. SOD (EC: 1.15.1.1) activity was quantified with a xanthine-xanthine oxidase system [4]. CAT (EC: 1.11.1.6), GR (EC: 1.6.4.2), and GST (EC: 2.5.1.18) activities were measured using the protocol of Hasanuzzaman et al. [21]. 
APX (EC: 1.11.1.11) activity was evaluated according to the method of Nakano and Asada [24], whereas MDHAR (EC: 1.6.5.4), DHAR (EC: 1.8.5.1), and GPX (EC: 1.11.1.9) activities were measured as described by Nahar et al. [7]. Gly I (EC: 4.4.1.5) and Gly II (EC: 3.1.2.6) activities were assayed according to Hasanuzzaman et al. [21] and Principato et al. [25], respectively.

\subsection{Determination of Ascorbate and Glutathione Content}

Fresh leaf tissue $(0.5 \mathrm{~g})$ was homogenized with $3 \mathrm{~mL} 5 \%$ trichloroacetic acid (TCA) [18]. After centrifugation $(11,500 \times g)$ for $15 \mathrm{~min}$ at $4{ }^{\circ} \mathrm{C}$, the collected supernatant was used for determination of ascorbate (AsA), DHA (dehydroascorbate), GSH, and oxidized glutathione (GSSG) pool sizes using the protocols of Parvin et al. [3].

\subsection{Determination of Methylglyoxal Content}

Methylglyoxal (MG) content was measured as described by Nahar et al. [7]. Leaves were first homogenized with $5 \%$ perchloric acid (PCA) and centrifuged at $11,000 \times g$. The supernatant was read at $288 \mathrm{~nm}$ spectrophotometrically after adding $N$-acetyl-L-cysteine.

\subsection{Statistical Analysis}

The measured data were statistically analyzed using XLSTAT 2018 software [26]; three replications were used for analysis of variance (ANOVA). The mean differences were compared using Fisher's least significant difference (LSD) test at the $5 \%$ level of significance.

\section{Results}

\subsection{Growth Restoration}

Salinity suppressed plant growth and dry matter accumulation, with a maximum decrease in shoot and root length, stem girth, and shoot and root FW and DW observed in the plants treated with $250 \mathrm{mM}$ salt compared to unstressed control plants; seedling growth was restored after the $48 \mathrm{~h}$ recovery period (Figures 1 and 2). The phenotypic appearance of the plants also indicated a reduction in growth and vigor under salt stress in relation to control plants, but a normal phenotype was restored after the recovery period (Figure 3).

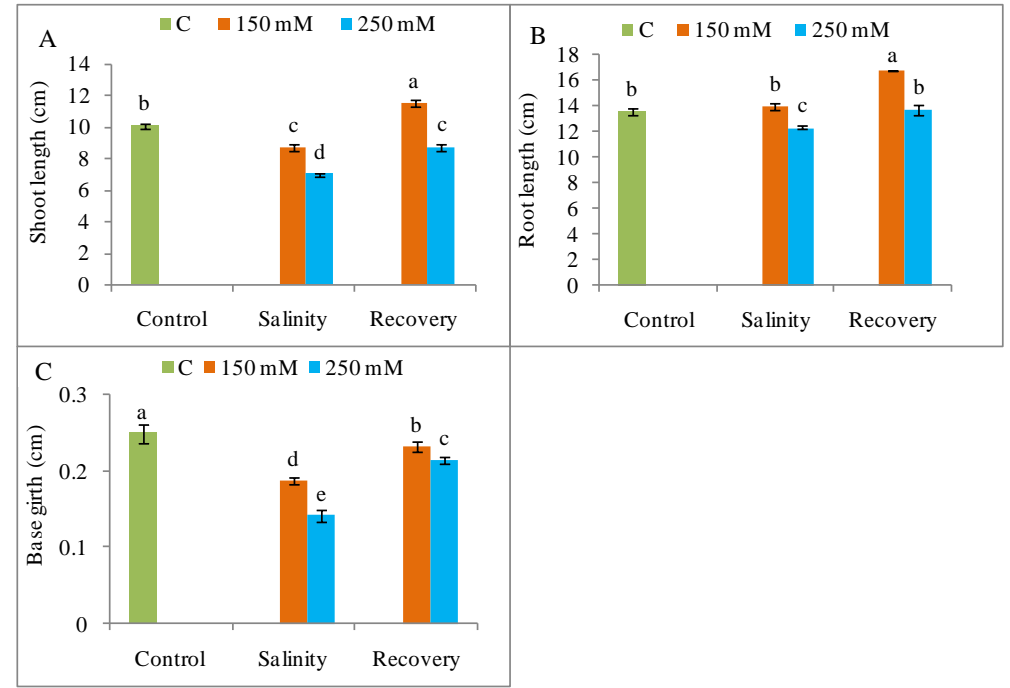

Figure 1. Tomato plant growth (A) shoot height, (B) root length, and (C) base girth under salinity $(150$ and $250 \mathrm{mM} \mathrm{NaCl})$ and after a $48 \mathrm{~h}$ recovery period. Data means $( \pm \mathrm{SD})$ were calculated from three replications. Statistically significant values are indicated by dissimilar letters (Fisher's least significant difference (LSD) test, $P \leq 0.05$ ). 


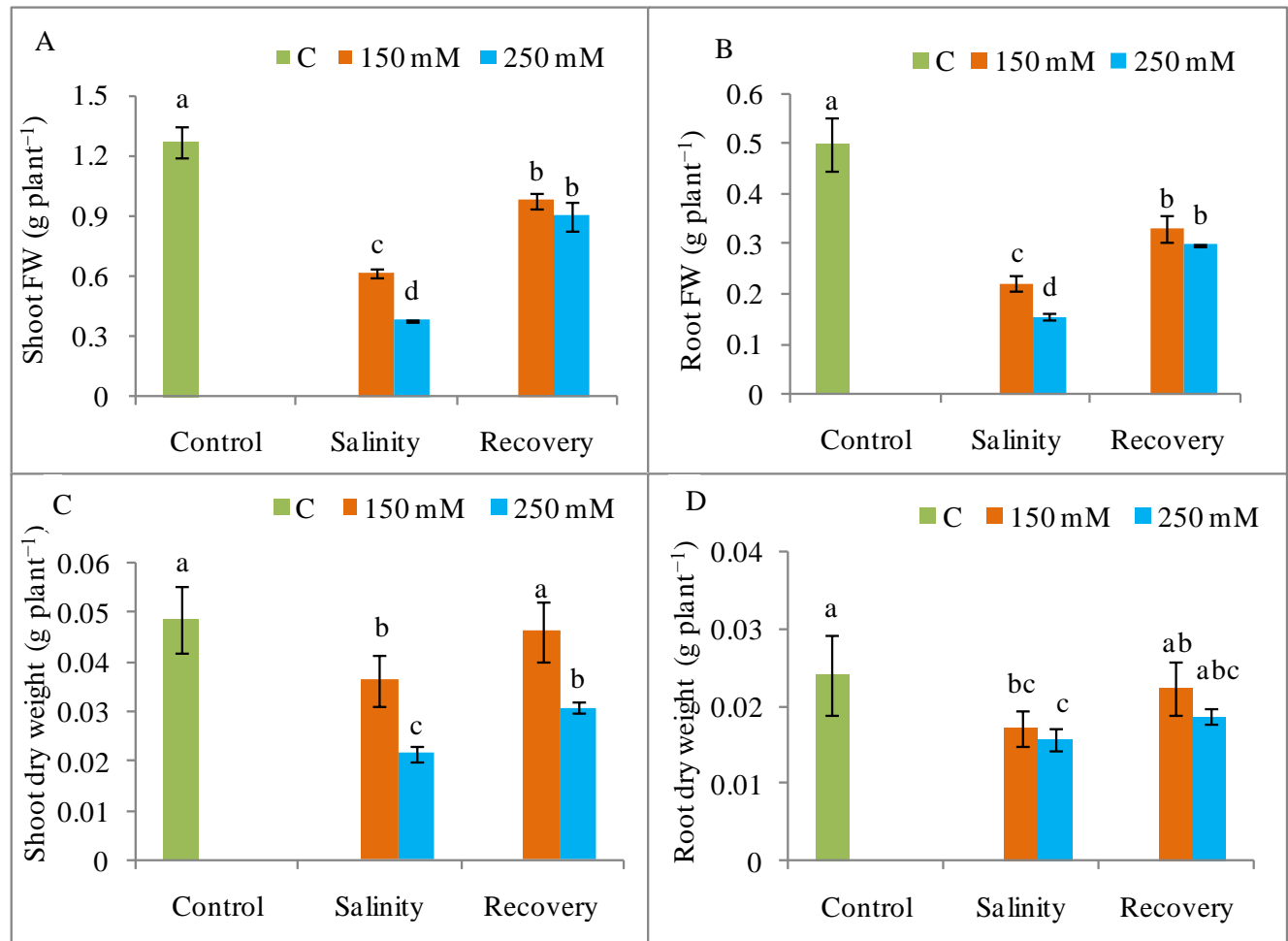

Figure 2. Plant biomass content (A) shoot fresh weight, (B) root fresh weight, (C) shoot dry weight, and (D) root dry weight in tomato plants under salinity (150 and $250 \mathrm{mM} \mathrm{NaCl}$ ) and after a $48 \mathrm{~h}$ recovery period. Data means $( \pm \mathrm{SD})$ were calculated from three replications. Statistically significant values are indicated by dissimilar letters (Fisher's LSD test, $P \leq 0.05$ ).

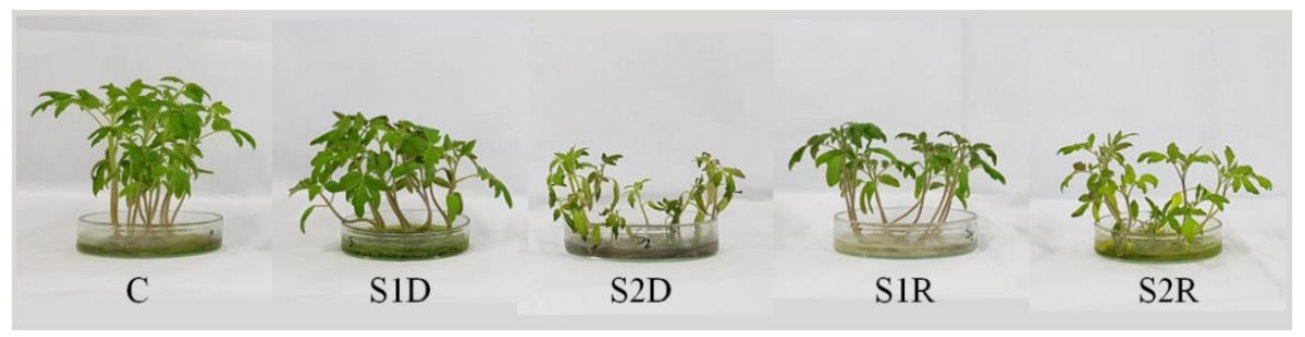

Figure 3. Visual differences of tomato plants under salinity (150 and $250 \mathrm{mM} \mathrm{NaCl})$ and after a $48 \mathrm{~h}$ recovery period. (C, control; S1D, $150 \mathrm{mM} \mathrm{NaCl}$; S2D, $250 \mathrm{mM} \mathrm{NaCl}$; S1R, recovered $150 \mathrm{mM} \mathrm{NaCl}$; and $\mathrm{S} 2 \mathrm{R}$, recovered $250 \mathrm{mM} \mathrm{NaCl}$ ).

\section{2. $\mathrm{Na}^{+}$Ion Homeostasis and Mineral Nutrition}

Salinity induced a higher $\mathrm{Na}^{+}$uptake, along with a lowered $\mathrm{K}^{+}, \mathrm{Ca}^{2+}$, and $\mathrm{Mg}^{2+}$ content, in both shoots and roots when compared to unstressed control plants. Compared to control, shoot $\mathrm{Na}^{+}$ accumulation increased by as much as 40 -fold, while root $\mathrm{Na}^{+}$content increased by 12 -fold in response to $250 \mathrm{mM} \mathrm{NaCl}$; however, the $\mathrm{Na}^{+}$content in both shoot and root tissues decreased after the $48 \mathrm{~h}$ recovery period (Figure $4 \mathrm{~A}, \mathrm{~B}$ ). The maximum $\mathrm{K}^{+}$loss compared to control, was observed in response to $250 \mathrm{mM} \mathrm{NaCl}$, resulting in an extreme increase in the $\mathrm{Na}^{+} / \mathrm{K}^{+}$value in both roots and shoots (Figure 4C-F). Exposure to $250 \mathrm{mM} \mathrm{NaCl}$ reduced the $\mathrm{Ca}^{2+}$ content in shoots and roots by $44 \%$ and $49 \%$, respectively; and the $\mathrm{Mg}^{2+}$ content by $52 \%$ and $41 \%$, respectively compared to unstressed control plants (Figure 5). Mineral homeostasis was restored, with a reduction in $\mathrm{Na}^{+}$and an increase in $\mathrm{K}^{+}$, $\mathrm{Ca}^{2+}$, and $\mathrm{Mg}^{2+}$ contents after the recovery period when compared to the stress condition (Figures 4 and 5). 


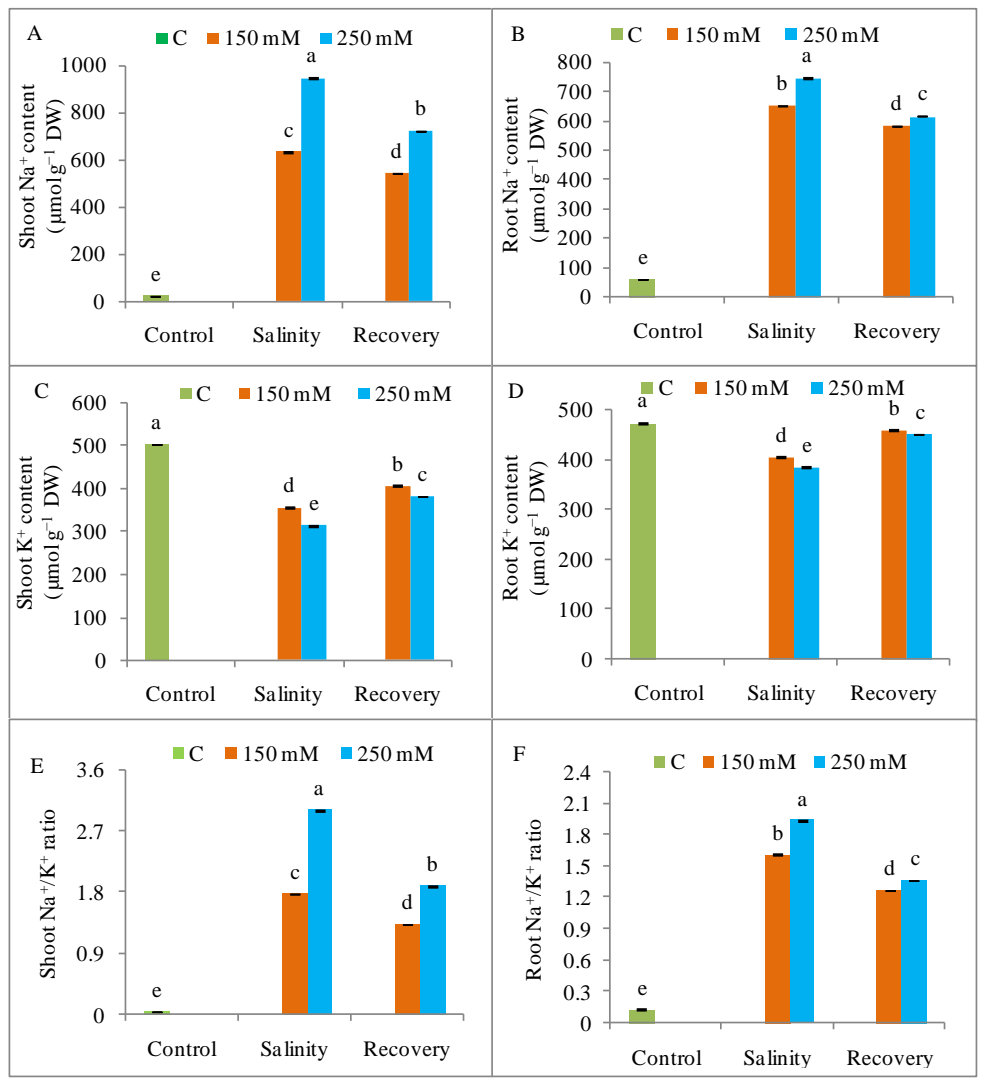

Figure 4. Content of $\mathrm{Na}^{+}, \mathrm{K}^{+}$and $\mathrm{Na}^{+} / \mathrm{K}^{+}$ratio (A) shoot $\mathrm{Na}^{+}$, (B) $\operatorname{root} \mathrm{Na}^{+}$, (C) Shoot $\mathrm{K}^{+}$, (D) Root $\mathrm{K}^{+}$, (E) Shoot $\mathrm{Na}^{+} / \mathrm{K}^{+}$ratio, and $(\mathrm{F})$ root $\mathrm{Na}^{+} / \mathrm{K}^{+}$in tomato plants under salinity $(150$ and $250 \mathrm{mM}$ $\mathrm{NaCl})$ and after a $48 \mathrm{~h}$ recovery period. Data means $( \pm \mathrm{SD})$ were calculated from three replications. Statistically significant values are indicated by dissimilar letters (Fisher's LSD test, $P \leq 0.05$ ).

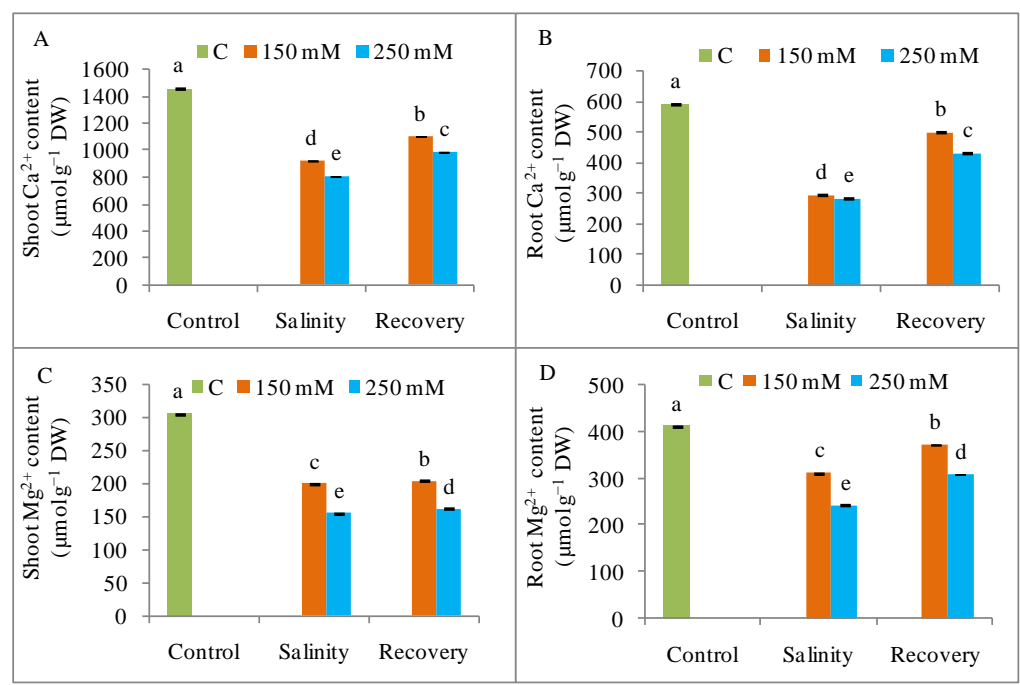

Figure 5. Content of $\mathrm{Ca}^{2+}$ and $\mathrm{Mg}^{2+}(\mathbf{A})$ shoot $\mathrm{Ca}^{2+},(\mathbf{B}) \operatorname{root} \mathrm{Ca}^{2+},(\mathbf{C})$ shoot $\mathrm{Mg}^{2+}$, and (D) root $\mathrm{Mg}^{2+}$ in tomato plants under salinity $(150$ and $250 \mathrm{mM} \mathrm{NaCl})$ and after a $48 \mathrm{~h}$ recovery period. Data means $( \pm \mathrm{SD})$ were calculated from three replications. Statistically significant values are indicated by dissimilar letters (Fisher's LSD test, $P \leq 0.05)$.

\subsection{Photosynthetic Pigment Content}

The leaf contents of $\mathrm{Chl} a$ and $\mathrm{Chl} b$ decreased by 33\% and 51\%, respectively, in response to $250 \mathrm{mM} \mathrm{NaCl}$ compare to control plants. The Chl $(a+b)$ content was therefore similarly reduced 
relative to the unstressed control plants. However, both $\mathrm{Chl} a$ and $\mathrm{Chl} b$ contents were increased respective to the relevant stress treatments after the recovery period (Figure 6A-C). Car content also decreased by $42 \%$ and $53 \%$ in response to 150 and $250 \mathrm{mM} \mathrm{NaCl}$, respectively, and it increased after the recovery period (Figure 6D).

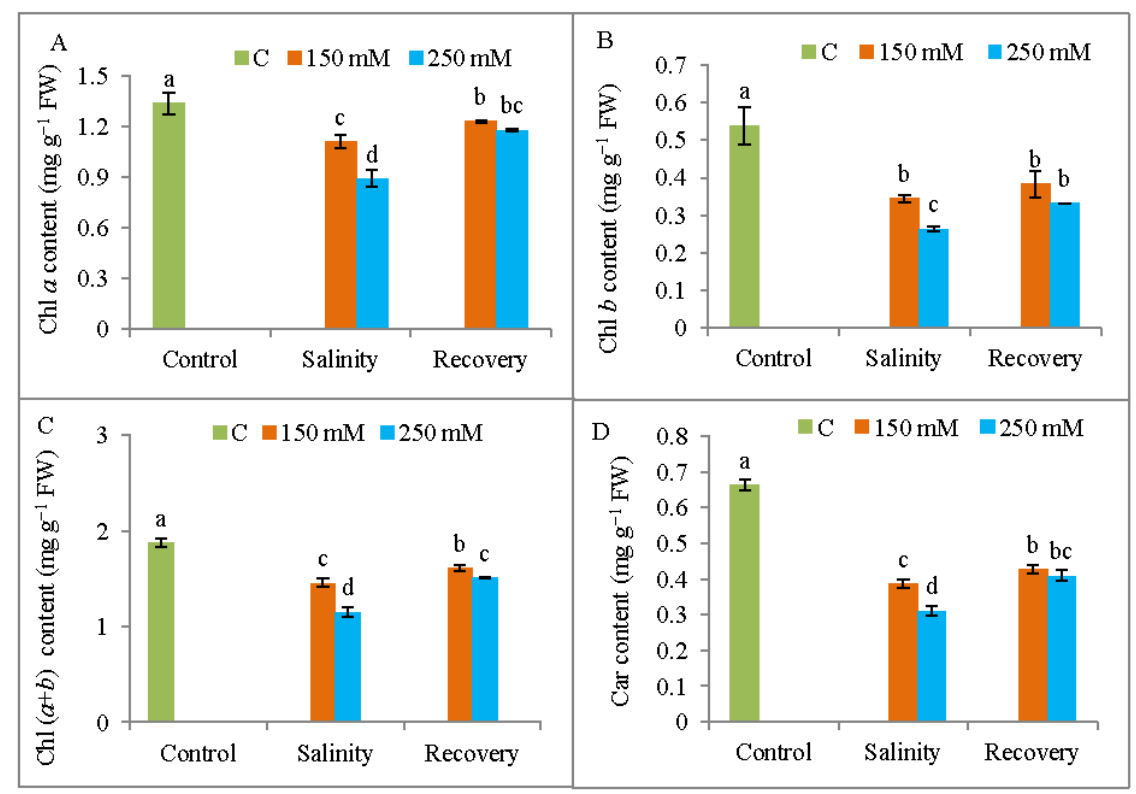

Figure 6. Photosynthetic pigments contents (A) chlorophyll $a$ (Chl $a)$, (B) chlorophyll $b$ (Chl $b),(\mathbf{C})$ Chl $(a+b)$, and (D) carotenoid in tomato plants under salinity (150 and $250 \mathrm{mM} \mathrm{NaCl})$ and after a $48 \mathrm{~h}$ recovery period. Data means $( \pm \mathrm{SD})$ were calculated from three replications. Statistically significant values are indicated by dissimilar letters (Fisher's LSD test, $P \leq 0.05$ ).

\subsection{Osmotic Adjustment and RWC}

Proline levels were greatly increased by salt exposure compared to control (Figure 7A), but these levels declined significantly after the recovery period, by $68 \%$ and $72 \%$ in the plants treated with 150 and $250 \mathrm{mM} \mathrm{NaCl}$, respectively. Salt stress reduced the leaf RWC, but this was restored after the recovery period (Figure 7B).

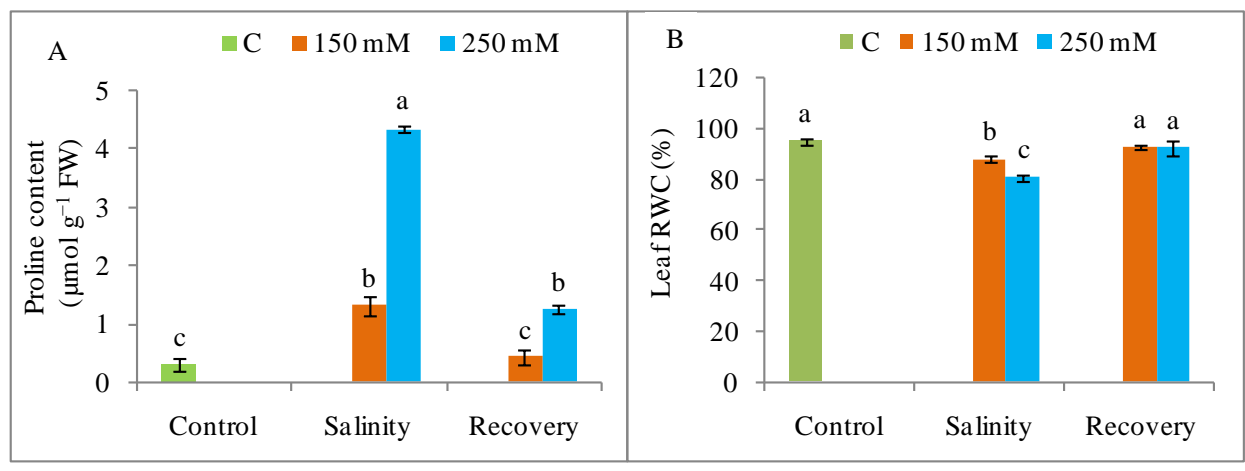

Figure 7. Osmotic status (A) proline (Pro) content, (B) leaf relative water content (RWC) in tomato plants under salinity $(150$ and $250 \mathrm{mM} \mathrm{NaCl})$ and after a $48 \mathrm{~h}$ recovery period. Data means $( \pm \mathrm{SD})$ were calculated from three replications. Statistically significant values are indicated by dissimilar letters (Fisher's LSD test, $P \leq 0.05$ ).

\subsection{Oxidative Stress}

The $\mathrm{H}_{2} \mathrm{O}_{2}$ production was higher under $\mathrm{NaCl}$ stress than in the unstressed control condition (Figure 8A), as also revealed by histochemical staining (Figure 9). The generation of ROS was lower 
after the recovery period than with stress alone (Figures 8A and 9). As documented in Figure 8B, the salt treatments (150 and $250 \mathrm{mM}$ ) also stimulated the activity of LOX, but this activity declined to control levels after the recovery period (Figure 8A,B). Compared to control, lipid peroxidation was increased by salt stress but returned to control levels after the recovery period (Figure 8C). Salt stress caused a higher and dose-dependent electrolyte leakage (EL) from both roots and leaves compared to unstressed plants, and this leakage was also reduced after the recovery period (Figure 10).

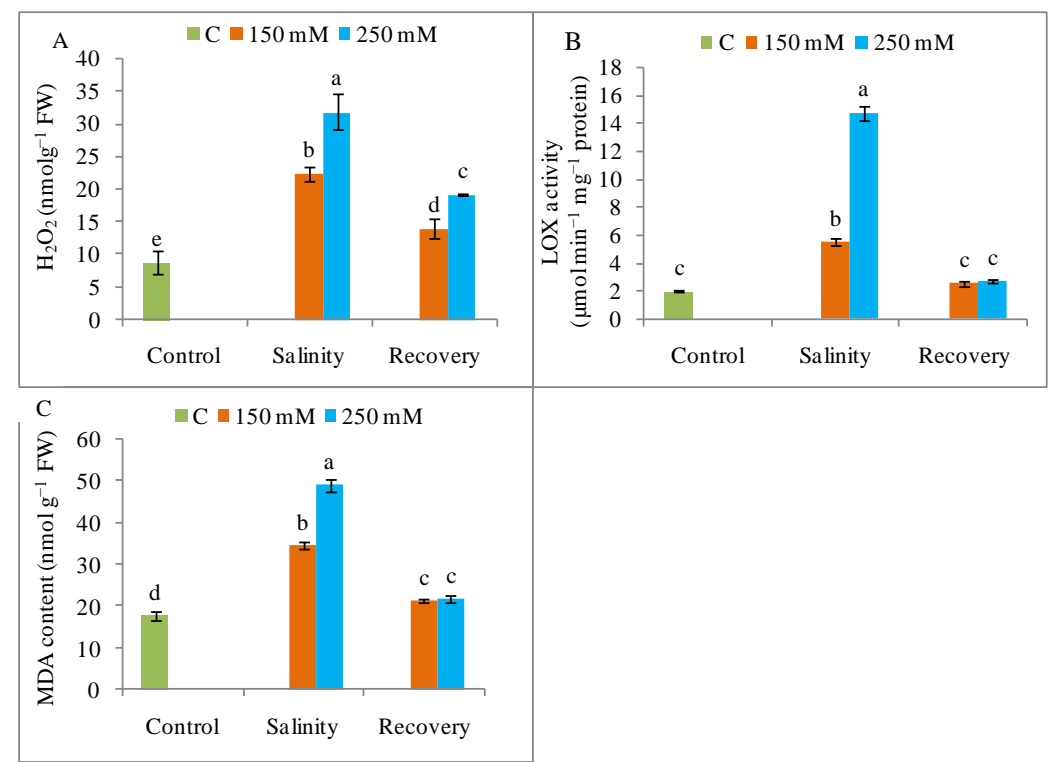

Figure 8. Oxidative stress markers (A) $\mathrm{H}_{2} \mathrm{O}_{2}$ content, (B) lipoxygenase (LOX) activity, (C) malondialdehyde (MDA) content in tomato plants under salinity $(150$ and $250 \mathrm{mM} \mathrm{NaCl})$ and after a $48 \mathrm{~h}$ recovery period. Data means $( \pm \mathrm{SD})$ were calculated from three replications. Statistically significant values are indicated by dissimilar letters (Fisher's LSD test, $P \leq 0.05$ ).

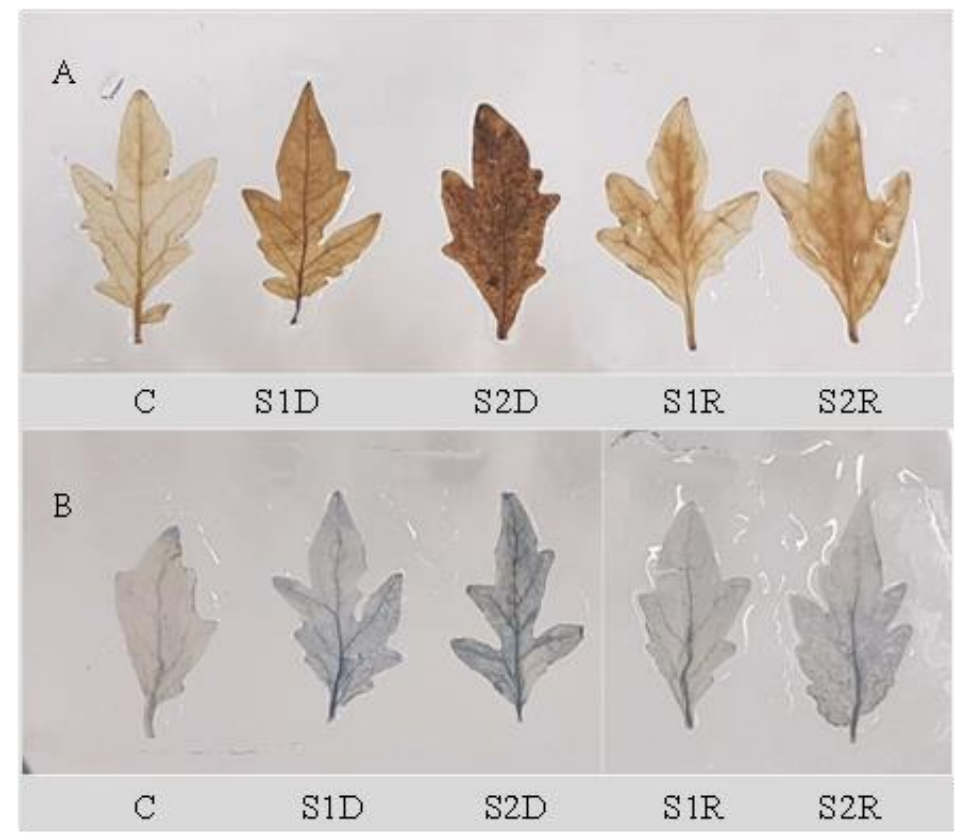

Figure 9. Histochemical detection of oxidative stress $\left(\mathbf{A}, \mathrm{H}_{2} \mathrm{O}_{2} ; \mathbf{B}, \mathrm{O}_{2}{ }^{\bullet-}\right)$ in tomato plants leaves under salinity (150 and $250 \mathrm{mM} \mathrm{NaCl})$ and after a $48 \mathrm{~h}$ recovery period. Data means $( \pm \mathrm{SD})$ were calculated from three replications. Statistically significant values are indicated by dissimilar letters (Fisher's LSD test, $P \leq 0.05)$. 


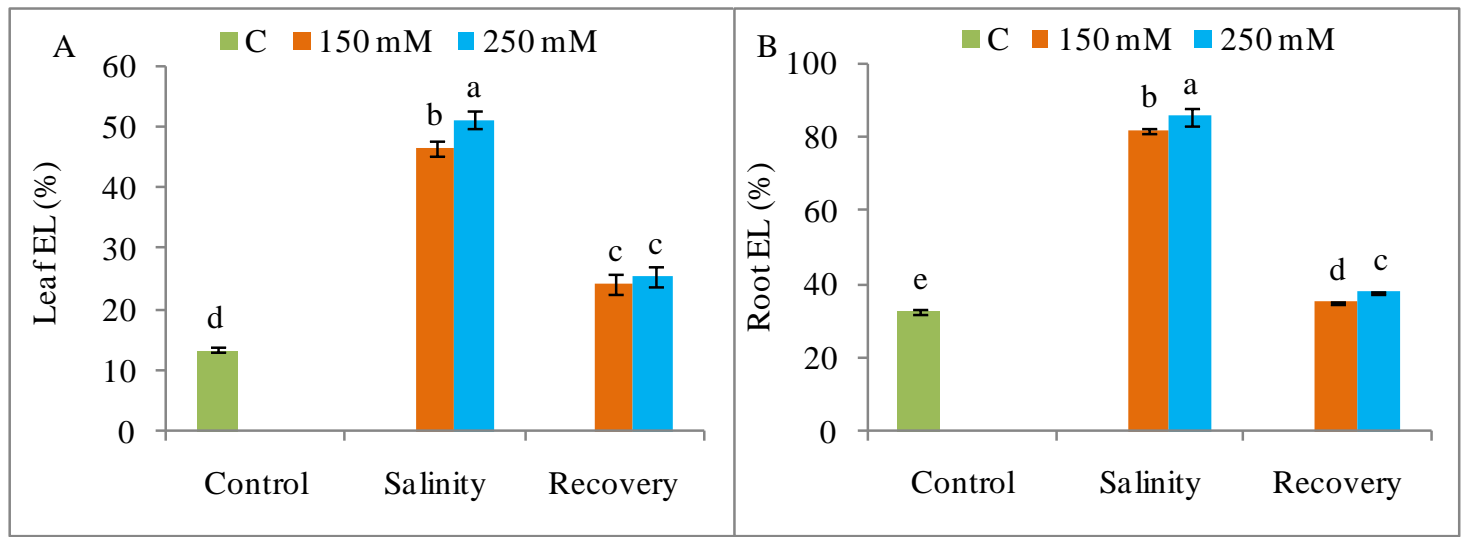

Figure 10. Electrolyte leakage (A) leaf, (B) root in tomato plants under salinity (150 and $250 \mathrm{mM} \mathrm{NaCl})$ and after a $48 \mathrm{~h}$ recovery period. Data means $( \pm \mathrm{SD})$ were calculated from three replications. Statistically significant values are indicated by dissimilar letters (Fisher's LSD test, $P \leq 0.05$ ).

\subsection{Antioxidant Enzyme Activities}

When compared with unstressed control plants, the SOD activity was increased by $30 \%$ and $43 \%$ after treatment with 150 and $250 \mathrm{mM} \mathrm{NaCl}$, respectively (Figure 11A), whereas SOD activity decreased after the recovery period. Compared to control, CAT activity was decreased by salt stress but was restored to the control level after the recovery period (Figure 11B).

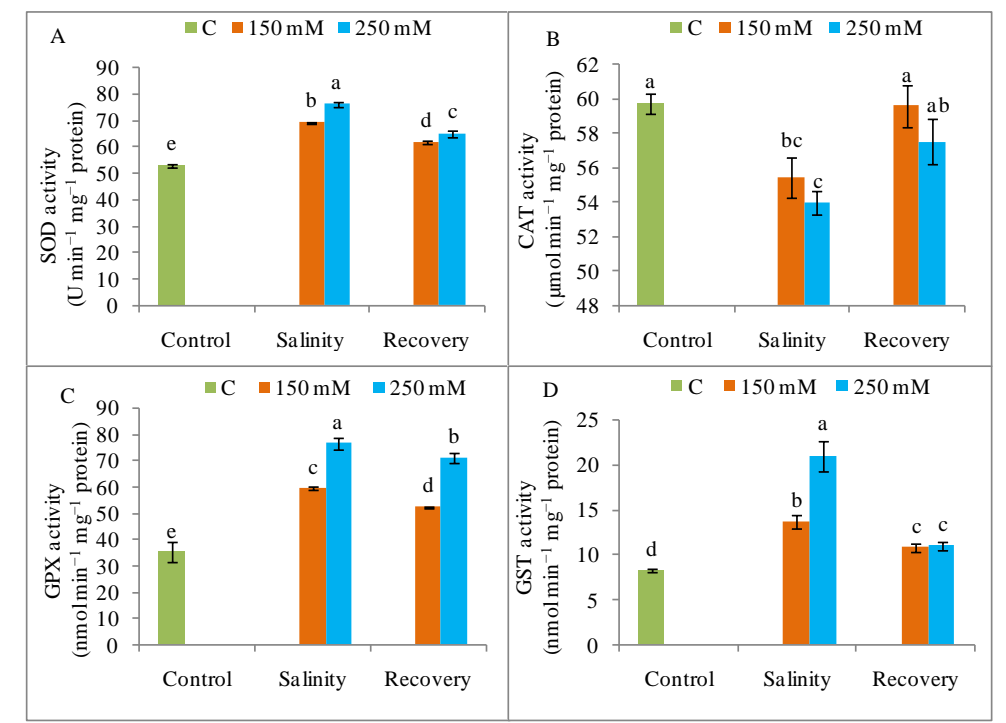

Figure 11. (A) Activities of superoxide dismutase (SOD), (B) catalase (CAT), (C) glutathione peroxidase (GPX), and (D) glutathione S-transferase (GST) in tomato plants under salinity (150 and $250 \mathrm{mM} \mathrm{NaCl}$ ) and after a $48 \mathrm{~h}$ recovery period. Data means $( \pm \mathrm{SD})$ were calculated from three replications. Statistically significant values are indicated by dissimilar letters (Fisher's LSD test, $P \leq 0.05$ ).

The APX activity was significantly increased by salinity $(250 \mathrm{mM} \mathrm{NaCl})$ when compared to the unstressed control condition, but this activity declined after the recovery period (Figure 12A). The MDHAR activity was increased by salt stress compared to control, but its activity doubled after the recovery period (Figure 12B). Compared to control, the DHAR activity increased noticeably under salt stress (Figure 12B), but declined again after the recovery period (Figure 12C). The GR activity was slightly decreased by salt exposure compared with the unstressed condition, but increased after the recovery period (Figure 12D). The thiol-dependent enzymes, GPX and GST, showed increased activity in response to $\mathrm{NaCl}$ stress compared to control, but both these activities were reduced after the recovery period (Figure 11C,D). 


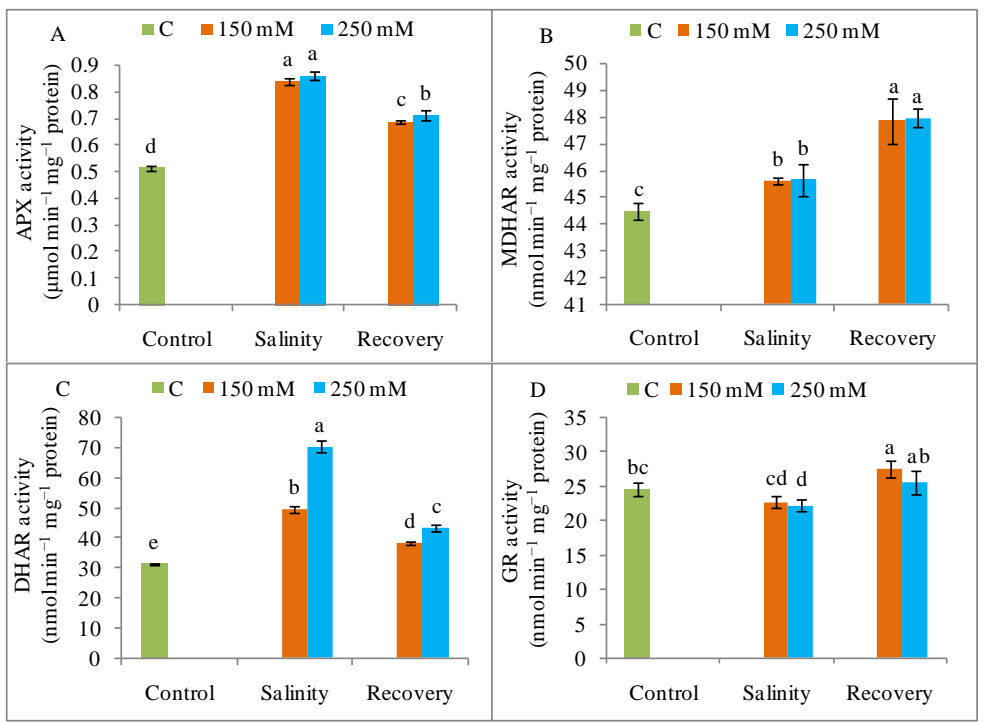

Figure 12. Activities of ascorbate peroxidase (APX) (A), monodehydroascorbate reductase (MDHAR) (B), dehydroascorbate reductase (DHAR) (C), and glutathione reductase (GR) (D) in tomato plants under salinity $(150$ and $250 \mathrm{mM} \mathrm{NaCl})$ and after a $48 \mathrm{~h}$ recovery period. Data means $( \pm \mathrm{SD})$ were calculated from three replications. Statistically significant values are indicated by dissimilar letters (Fisher's LSD test, $P \leq 0.05$ ).

\subsection{Non-Enzymatic Antioxidant Levels}

A significant reduction in AsA content and a significant increase in DHA content were observed in response to both 150 and $250 \mathrm{mM} \mathrm{NaCl}$ treatments when compared to the unstressed control plants, but these levels approached control levels after the recovery period (Figure 13A,B). Compared to control, the GSH content increased in response to salinity stress and continued to increase after the recovery period (Figure 13D). The GSSG content was increased by salinity stress in comparison with control, but the levels declined after the recovery period (Figure 13E). Salt stress reduced the redox ratio of AsA/DHA and GSH/GSSG compared with unstressed ones, but these ratios were again increased after the recovery period (Figure 13C,F).

\subsection{MG Detoxification}

Salinity increased Gly I and decreased Gly II activity, while increasing the MG content in the salt-stressed plants compared to the unstressed control plants (Figure 14). Compared to stressed conditions, the Gly I activity declined, the Gly II activity increased, and the MG content decreased during the recovery period (Figure 14). 


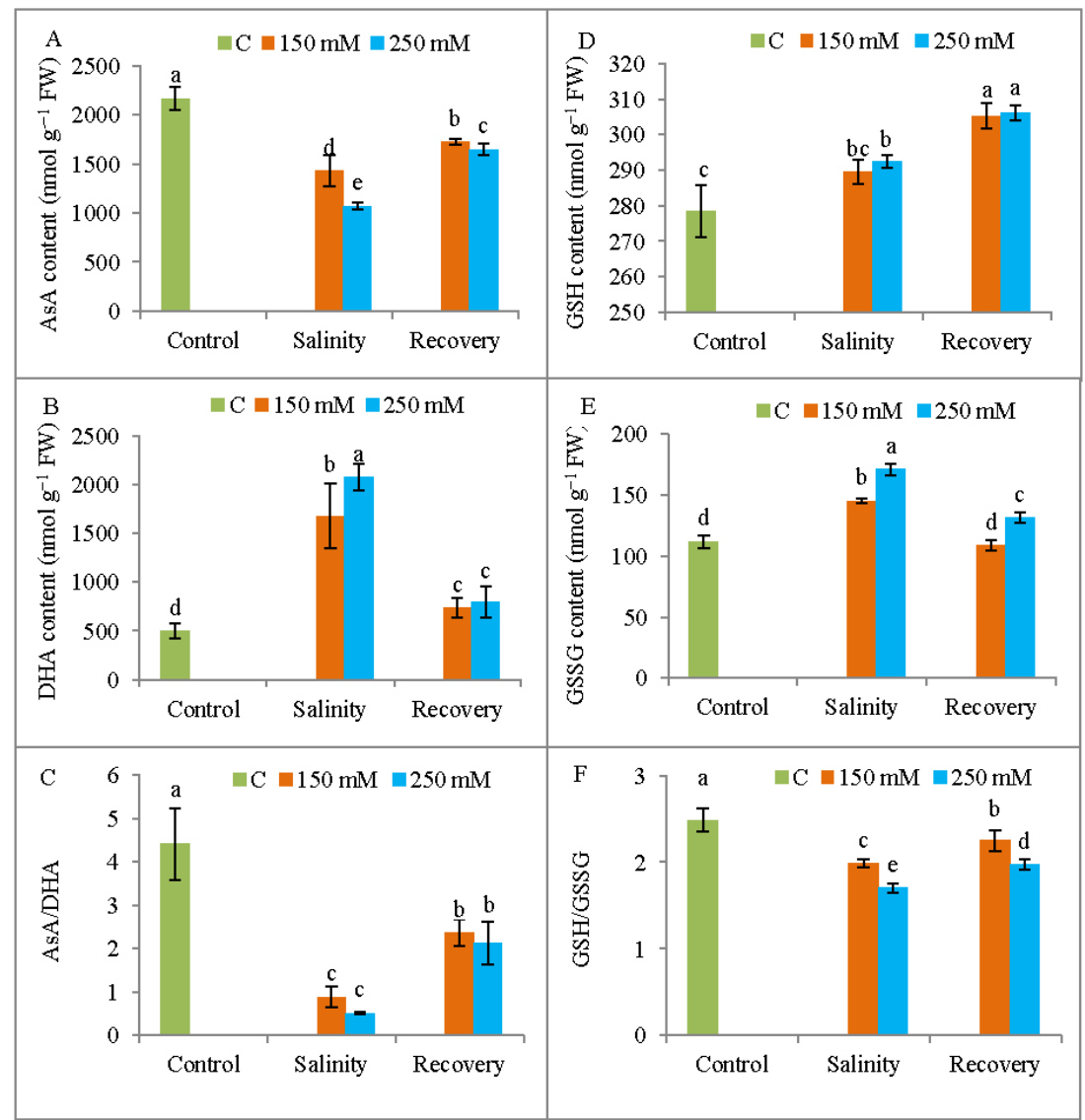

Figure 13. Content of AsA (A), dehydroascorbate (DHA) (B), AsA/DHA ratio (C), GSH (D), GSSG(E), and GSH/GSSH ratio (F) in tomato plants under salinity (150 and $250 \mathrm{mM} \mathrm{NaCl}$ ) and after a $48 \mathrm{~h}$ recovery period. Data means $( \pm \mathrm{SD})$ were calculated from three replications. Statistically significant values are indicated by dissimilar letters (Fisher's LSD test, $P \leq 0.05$ ).

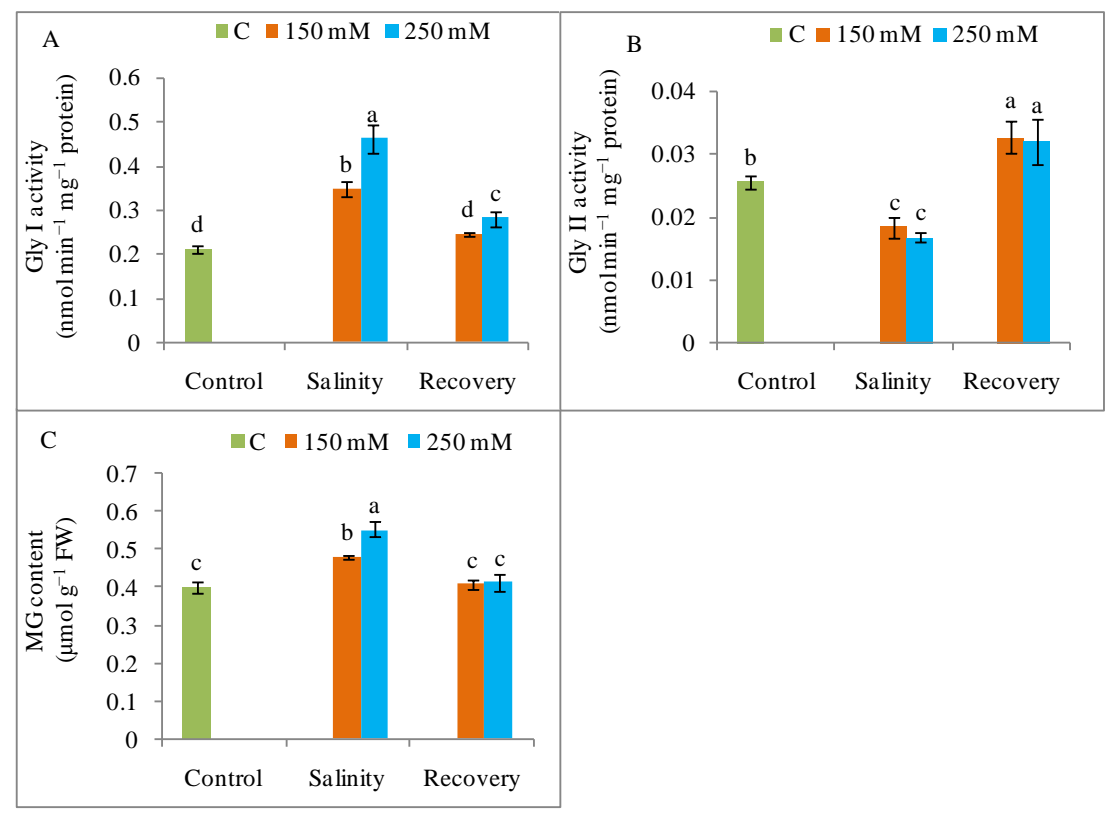

Figure 14. Methylglyoxalase detoxification (A) and activities of glyoxalase enzymes (B) Gly I, (C) Gly II in tomato plants under salinity ( 150 and $250 \mathrm{mM} \mathrm{NaCl}$ ) and after a $48 \mathrm{~h}$ recovery period. Data means $( \pm$ SD) were calculated from three replications. Statistically significant values are indicated by dissimilar letters (Fisher's LSD test, $P \leq 0.05$ ). 


\section{Discussion}

Salt stress drastically inhibits seedling growth and biomass accumulation [3]. Previous reports by Manai et al. [27] and Martinez et al. [28] showed a reduction in the FW of tomato shoots and roots, as well as a decrease in root length, in response to salinity. The reason for salinity-induced growth restriction might be a salt-mediated reduction in cell growth [29]. In the present study, tomato plants showed a significant restoration of normal growth after the recovery period. A similar recovery of growth, indicated by increases in leaf area and shoot DW, has been previously reported for salt-stressed Vigna unguiculata [30]. Similarly, Acosta-Motos et al. [31] found that a recovery period after salinity stress restored growth in Eugenia myrtifolia L., in agreement with our findings. Under field conditions, salt stress recovery often happens due to normal irrigation or rainfall and growth restoration upon recovery implies a significant improvement in salinity tolerance after removal of a salt stress.

The reduced growth due to salinity stress indicates a need to study ion accumulation in plant cells. In the present case, tomato plants suffered from excess $\mathrm{Na}^{+}$accumulation and a consequent $\mathrm{K}^{+}$loss. Salinity depolarizes the root plasma membrane while activating the outward rectifying K-channels (GORK) of the guard cells, resulting in an increased $\mathrm{Na}^{+}$content and a decreased $\mathrm{K}^{+}$ levels [2,32]. The higher $\mathrm{Na}^{+}$content therefore disrupts the $\mathrm{Na}^{+} / \mathrm{K}^{+}$ratio and ion homeostasis [2,29]. The lower $\mathrm{Ca}^{2+}$ content observed in salinity-stressed tomato plants might indicate a replacement of $\mathrm{Ca}^{2+}$ by $\mathrm{Na}^{+}$. Some reports have suggested that high salinity displaces $\mathrm{Ca}^{2+}$ from the cell membrane, resulting in increased membrane permeability and a higher intracellular $\mathrm{Na}^{+}$content [2,7]. Removal of the salt stress significantly decreased the $\mathrm{Na}^{+}$content and the $\mathrm{K}^{+}$content increased, indicating a restoration of ion homeostasis, as evidenced by increasing levels of $\mathrm{Ca}^{2+}$ and $\mathrm{Mg}^{2+}$; these changes could be responsible for the observed restoration of seedling growth. The study by de Lacerda et al. [11] showed that the lower content of toxic ions in Sorghum bicolor seedlings after a salt stress was related to stress tolerance.

Salinity stress also hampers photosynthetic pigment synthesis, resulting in leaf chlorosis, as evident in many previous reports [33,34]. Ahmed et al. [35] and Martinez et al. [28] confirmed the loss of Chl synthesis in salt-stressed plants. The salt-induced reduction in Chl levels might be due to structural damage to the $\mathrm{Chl}$ molecules by increased chlorophyllase activity [33]. In the present study, the levels of $\mathrm{Chl} a, \mathrm{Chl} b, \mathrm{Chl}(a+b)$ and Car were restored in the stressed tomato plants after the recovery period, in agreement with previous findings by Acosta-Motos et al. [31]. Therefore, recovery treatments appear to increase plant tolerance and rejuvenate the plants for further growth by restoring Chl synthesis.

Apart from ion toxicity, salinity also causes osmotic stress by altering the water potential in both the growth medium and the plant body. In the present study, tomato plants suffered from osmotic stress indicated by the reduced leaf RWC. High concentrations of $\mathrm{NaCl}$ can injure the root system, resulting in lower water uptake [36]. In the present study, salinity increased the Pro levels, which may have increased stress tolerance in the plants by maintaining the osmotic potential, leaf expansion, and stomatal conductance, as well as photosynthesis [7]. Hence, the higher Pro levels observed in the stress-injured plants after the recovery period may indicate an active process for increasing stress tolerance. The recovery period appeared to result in a reduction in osmotic stress due to increased RWC [37].

Tomato plants also showed a quick recovery response from damage induced by high salt exposure, as indicated by the increase in metabolic activities designed to avoid the deleterious effects of short-duration salinity. Salinity increases the generation of $\mathrm{ROS}\left(\mathrm{H}_{2} \mathrm{O}_{2}, \mathrm{O}_{2}{ }^{\bullet-}\right)$ in plants, resulting in oxidative stress. The higher ROS levels cause oxidative damage, including peroxidation of lipid and proteins, pigment destruction, and nucleic acid and DNA damage, and ROS also impairs enzyme activities [28]. Here, a higher $\mathrm{H}_{2} \mathrm{O}_{2}$ content was detected under salt stress, indicating oxidative stress, and the level of this ROS increased with increasing salt concentration, in line with the findings reported separately by Manai et al. [27] and Martinez et al. [28]. Salinity also increases LOX activity, which causes lipid peroxidation. Interestingly, after the recovery period, the oxidative stress was reduced in the tomato plants, as confirmed by the reductions in ROS levels and LOX activity, as well as by the lower 
MDA content, in agreement with the results reported by Lv et al. [38]. Similarly, Acosta-Motos et al. [31] reported that elevated EL was relieved upon recovery from salinity in E. myrtifolia.

The observed restoration of growth in salt-stressed plants and the improvement in osmotic status and mineral homeostasis prompted our exploration of plant antioxidant defense mechanisms. Salt stress increased the SOD activity, which is in agreement with the findings of Ahmad et al. [35]. By contrast, the CAT enzyme works to scavenge toxic $\mathrm{H}_{2} \mathrm{O}_{2}$ [5], and yet the salt-stressed tomato plants showed a reduction in CAT activity under salinity. This finding might indicate a reduced capacity for $\mathrm{H}_{2} \mathrm{O}_{2}$ detoxification, which would result in greater oxidative damage. A similar behavior was reported in tomato by Manai et al. [27]. However, other vital components of this cycle, namely the APX enzyme and AsA, also scavenge toxic $\mathrm{H}_{2} \mathrm{O}_{2}$ and convert it to $\mathrm{H}_{2} \mathrm{O}$ [8]. In the present study, APX activity increased under salinity stress, whereas AsA decreased. The decrease in AsA content was accompanied by a higher DHA content, in agreement with the findings of Ahmad et al. [35], which also reduced AsA content and elevated APX activities in salt-stressed tomato. Acosta-Motos et al. [31] also reported a reduction in AsA content in plants under saline conditions. After a recovery period, the salt-stressed tomato plants showed decreased APX activity and a reduced DHA content, along with a greater AsA content. After the recovery period, the $\mathrm{H}_{2} \mathrm{O}_{2}$ generation had decreased, so less AsA was used to scavenge the ROS and the DHA content declined. The AsA content is modulated by MDHAR and DHAR activities, as well as APX [10], and our salt-stressed tomato plants showed higher activities of MDHAR and DHAR.

Salinity stress also increased the GSH and GSSG content, and reduced the GSH/GSSH ratio, but this ratio increased after the recovery period. Ahmad et al. [35] also reported an increase in GSH content in tomato after salt exposure, and Acosta-Motos et al. [31] also found increased GSH and GSSG contents after a recovery period in salinity-affected plants. In the present study, GR activity was increased in salt-stressed plants. Manai et al. [27] also reported increased GR activity in salt-stressed tomato. Further enhancement of GR activity was observed after the recovery period in saline-treated plants, resulting in further direct modulation of the GSH and GSSG contents and improved plant tolerance. Acosta-Motos et al. [31] showed an increase in GR in salt-treated E. myrtifolia, but a reduction in GR activity during a recovery period. Tomato plants in the present study also showed increased activity of GPX and GST under salt stress, but this activity declined after the recovery period, which might be attributed to a decreased $\mathrm{H}_{2} \mathrm{O}_{2}$ content. Previous reports have also shown increased GPX activity in tomato due to salinity [27]. The levels of most of the non-enzymatic and enzymatic antioxidants were increased after the recovery treatment, indicating an enhanced salt tolerance.

Higher MG content in the salt-treated plants was due to the lower activities of glyoxalase enzymes, but these responses were reversed after the stress recovery. Gly I activity was highly involved in MG detoxification under salinity and the concomitant decrease in lowered GSH content. But, upon recovery, Gly II activity increased while Gly I activity decreased thus reducing MG generation, which might have contributed to a higher content of GSH. Therefore, the glyoxalase system was also stimulated during the recovery period in salt-stressed plants, thereby contributing to higher GSH content for controlling ROS and better salt tolerance in tomato plants.

\section{Conclusions}

Salt-stressed tomato plants recover very quickly at the seedling stage by invoking their efficient antioxidant defense and glyoxalase systems. Salt stress restricted seedling growth by imposing oxidative, ionic, and osmotic stresses, along with suppression of these plant defense mechanisms. The recovery period allowed the removal of the salt-induced ionic toxicity by reducing the $\mathrm{Na}^{+}$ accumulation and increasing $\mathrm{K}^{+}, \mathrm{Ca}^{2+}$, and $\mathrm{Mg}^{2+}$ contents in both the shoots and roots. The recovery treatment also allowed restoration of the photosynthetic pigment levels in salt-injured plant leaves, which correlated with better seedling growth. The Pro content was reduced, concomitantly with higher RWC, after the recovery period, thereby confirming the alleviation of salt-induced osmotic stress. During the recovery period, both non-enzymatic and enzymatic antioxidants, along with 
glyoxalase enzymes, were apparently able to detoxify the salt-induced ROS. Interestingly, Gly II, rather than Gly 1, showed a pronounced involvement in MG detoxification in the recovered seedling. The positive recovery of tomato plants from the toxic effects of a saline stress, as observed in the present study, indicates a need for further in-depth studies that include phytohormone signaling and crosstalk responses.

Author Contributions: Conceptualization, K.P., M.H., K.N., and M.F.; methodology, K.P, M.H.M.B.B., and M.H.; validation, M.H.; formal analysis, M.H.; investigation, K.P., M.H.M.B.B., and S.M.M.; resources, writing-original draft preparation, K.P., K.N., and M.H.M.B.B.; writing—review and editing, K.N., M.H., and M.F.; visualization, K.P.; supervision, M.H. and M.F.

Funding: This research was funded by the Ministry of Education, Culture, Sports, Science and Technology (MEXT), Japan.

Acknowledgments: This study was funded by the Ministry of Education, Culture, Sports, Science and Technology (MEXT), Japan. Thanks to Md. Shahadat Hossain, Faculty of Agriculture, Kagawa University, Japan for helping in the methodology. We also thank A.A.C. Masud and Mahmodul Hasan Sohag, Faculty of Agriculture, Kagawa University, Japan for their kind assistance during experimentation.

Conflicts of Interest: The authors declare no conflict of interest.

\section{References}

1. Hasanuzzaman, M.; Oku, H.; Nahar, K.; Bhuyan, M.H.M.B.; Al Mahmud, J.; Baluska, F.; Fujita, M. Nitric oxide-induced salt stress tolerance in plants: ROS metabolism, signaling, and molecular interactions. Plant Biotechnol. Rep. 2018, 12, 77-92. [CrossRef]

2. Rahman, A.; Nahar, K.; Hasanuzzaman, M.; Fujita, M. Calcium supplementation improves $\mathrm{Na}^{+} / \mathrm{K}^{+}$ratio, antioxidant defense and glyoxalase systems in salt-stressed rice seedlings. Front. Plant Sci. 2016, 7, 609. [CrossRef] [PubMed]

3. Parvin, K.; Hasanuzzaman, M.; Bhuyan, M.H.M.; Mohsin, S.M.; Fujita, M. Quercetin mediated salt tolerance in tomato through the enhancement of plant antioxidant defense and glyoxalase systems. Plants 2019, 8, 247. [CrossRef] [PubMed]

4. El-Shabrawi, H.; Kumar, B.; Kaul, T.; Reddy, M.K.; Singla-Pareek, S.L.; Sopory, S.K. Redox homeostasis, antioxidant defense, and methylglyoxal detoxification as markers for salt tolerance in Pokkali rice. Protoplasma 2010, 245, 85-96. [CrossRef] [PubMed]

5. Hasanuzzaman, M.; Nahar, K.; Hossain, M.S.; Anee, T.I.; Parvin, K.; Fujita, M. Nitric oxide pretreatment enhances antioxidant defense and glyoxalase systems to confer PEG-induced oxidative stress in rapeseed. J. Plant Interact. 2017, 12, 323-331. [CrossRef]

6. Soares, C.; Carvalho, M.E.; Azevedo, R.A.; Fidalgo, F. Plants facing oxidative challenges-A little help from the antioxidant networks. Environ. Exp. Bot. 2019, 161. [CrossRef]

7. Nahar, K.; Hasanuzzaman, M.; Alam, M.M.; Rahman, A.; Suzuki, T.; Fujita, M. Polyamine and nitric oxide crosstalk: Antagonistic effects on cadmium toxicity in mung bean plants through upregulating the metal detoxification, antioxidant defense and methylglyoxal detoxification systems. Ecotoxicol. Environ. Saf. 2016, 126, 245-255. [CrossRef]

8. Hasanuzzaman, M.; Nahar, K.; Alam, M.M.; Bhuyan, M.B.; Oku, H.; Fujita, M. Exogenous nitric oxide pretreatment protects Brassica napus L. seedlings from paraquat toxicity through the modulation of antioxidant defense and glyoxalase systems. Plant Physiol. Biochem. 2018, 126, 173-186.

9. Gill, S.S.; Tuteja, N. Reactive oxygen species and antioxidant machinery in abiotic stress tolerance in crop plants. Plant Physiol. Biochem. 2010, 48, 909-930. [CrossRef]

10. Mahmud, J.A.; Hasanuzzaman, M.; Nahar, K.; Bhuyan, M.H.M.B.; Fujita, M. Insights into citric acid-induced cadmium tolerance and phytoremediation in Brassica juncea L.: Coordinated functions of metal chelation, antioxidant defense and glyoxalase systems. Ecotoxicol. Environ. Saf. 2018, 147, 990-1001. [CrossRef]

11. De Lacerda, C.F.; Cambraia, J.; Oliva, M.A.; Ruiz, H.A. Changes in growth and in solute concentrations in sorghum leaves and roots during salt stress recovery. Environ. Exp. Bot. 2005, 54, 69-76. [CrossRef]

12. Cavalcanti, F.R.; Lima, J.P.M.S.; Ferreira-Silva, S.L.; Viégas, R.A.; Silveira, J.A.G. Roots and leaves display contrasting oxidative response during salt stress and recovery in cowpea. J. Plant Physiol. 2007, 164, 591-600. [CrossRef] [PubMed] 
13. Hoagland, D.R.; Arnon, D.I. The Water-Culture Method for Growing Plants without Soil; Circ No. 347; California Agricultural Experiment Station: Davis, CA, USA, 1950.

14. Wellburn, A.R. The spectral determination of chlorophylls $a$ and $b$, as well as total carotenoids, using various solvents with spectrophotometers of different resolution. J. Plant Physiol. 1994, 144, 307-313. [CrossRef]

15. Barrs, H.D.; Weatherley, P.E. A re-examination of the relative turgidity technique for estimating water deficits in leaves. Aust. J. Biol. Sci. 1962, 15, 413-428. [CrossRef]

16. Bates, L.S.; Waldren, R.P.; Teari, D. Rapid determination of free proline for water stress studies. Plant Soil 1973, 39, 205-207. [CrossRef]

17. Heath, R.L.; Packer, L. Photo peroxidation in isolated chloroplast: I. Kinetics and stoichiometry of fatty acid peroxidation. Arch. Biochem. Biophys. 1968, 125, 189-198. [CrossRef]

18. Hossain, M.S.; Hasanuzzaman, M.; Sohag, M.M.H.; Bhuyan, M.H.M.B.; Fujita, M. Acetate-induced modulation of ascorbate: Glutathione cycle and restriction of sodium accumulation in shoot confer salt tolerance in Lens culinaris Medik. Physiol. Mol. Biol. Plants 2019, 25, 443-455. [CrossRef]

19. Chen, F.; Wang, F.; Wu, F.; Mao, W.; Zhang, G.; Zhou, M. Modulation of exogenous glutathione in antioxidant defense system against $\mathrm{Cd}$ stress in the two barley genotypes differing in Cd tolerance. Plant Physiol. Biochem. 2010, 48, 663-672. [CrossRef]

20. Dionisio-Sese, M.L.; Tobita, S. Antioxidant responses of rice seedlings to salinity stress. Plant Sci. 1998, 135, 1-9. [CrossRef]

21. Hasanuzzaman, M.; Hossain, M.A.; Fujita, M. Nitric oxide modulates antioxidant defense and the methylglyoxal detoxification system and reduces salinity-induced damage of wheat seedlings. Plant Biotechnol. 2011, 5, 353-365. [CrossRef]

22. Bradford, M. A rapid and sensitive method for the quantitation of microgram quantities of protein utilizing the principle of protein-dye binding. Anal. Biochem. 1976, 72, 248-254. [CrossRef]

23. Doderer, A.; Kokkelink, I.; Van der Veen, S.; Valk, B.; Schram, A.; Douma, A. Purification and characterization of two lipoxygenase isoenzymes from germinating barley. Biochim. Biophys. Acta 1992, 112, 97-104. [CrossRef]

24. Nakano, Y.; Asada, K. Hydrogen peroxide is scavenged by ascorbate specific peroxidase in spinach chloroplasts. Plant Cell Physiol. 1981, 22, 867-880.

25. Principato, G.B.; Rosi, G.; Talesa, V.; Govannini, E.; Uolila, L. Purification and characterization of two forms of glyoxalase II from rat liver and brain of Wistar rats. Biochem. Biophys. Acta 1987, 911, 349-355. [CrossRef]

26. Addinsoft. XLSTAT v. 2018: Data Analysis and Statistics Software for Microsoft Excel; Addinsoft: Paris, France, 2018.

27. Manai, J.; Gouia, H.; Corpas, F.J. Redox and nitric oxide homeostasis are affected in tomato (Solanum lycopersicum) roots under salinity-induced oxidative stress. J. Plant Physiol. 2014, 171, 1028-1035. [CrossRef] [PubMed]

28. Martinez, V.; Nieves-Cordones, M.; Lopez-Delacalle, M.; Rodenas, R.; Mestre, T.C.; Garcia-Sanchez, F.; Rubio, F.; Nortes, P.A.; Mittler, R.; Rivero, R.M. Tolerance to stress combination in tomato plants: New insights in the protective role of melatonin. Molecule 2018, 23, 535. [CrossRef]

29. Queirós, F.; Rodrigues, J.A.; Almeida, J.M.; Almeida, D.P.; Fidalgo, F. Differential responses of the antioxidant defence system and ultrastructure in a salt-adapted potato cell line. Plant Physiol. Biochem. 2011, 49, 1410-1419. [CrossRef]

30. De Abreu, C.E.B.; dos Santos Araújo, G.; de Oliveira Monteiro-Moreira, A.C.; Costa, J.H.; de Brito Leite, H.; Moreno, F.B.M.B.; Prisco, J.T.; Gomes-Filho, E. Proteomic analysis of salt stress and recovery in leaves of Vigna unguiculata cultivars differing in salt tolerance. Plant Cell Rep. 2014, 33, 1289-1306. [CrossRef]

31. Acosta-Motos, J.R.; Diaz-Vivancos, P.; Álvarez, S.; Fernández-García, N.; Sanchez-Blanco, M.J.; Hernández, J.A. Physiological and biochemical mechanisms of the ornamental Eugenia myrtifolia L. plants for coping with $\mathrm{NaCl}$ stress and recovery. Planta 2015, 242, 829-846. [CrossRef]

32. Bose, J.; Rodrigo-Moreno, A.; Shabala, S. ROS homeostasis in halophytes in the context of salinity stress tolerance. J. Exp. Bot. 2014, 65, 1241-1257. [CrossRef]

33. Nazar, R.; Khan, M.I.R.; Iqbal, N.; Masood, A.; Khan, N.A. Involvement of ethylene in reversal of salt-inhibited photosynthesis by sulfur in mustard. Physiol. Plant. 2014, 152, 331-344. [CrossRef] [PubMed]

34. Ahmad, P.; Hashem, A.; Abd-Allah, E.F.; Alqarawi, A.A.; John, R.; Egamberdieva, D.; Gucel, S. Role of Trichoderma harzianum in mitigating $\mathrm{NaCl}$ stress in Indian mustard (Brassica juncea L.) through antioxidative defense system. Front. Plant Sci. 2015, 6, 868. [CrossRef] [PubMed] 
35. Ahmad, P.; Abass Ahanger, M.; Nasser Alyemeni, M.; Wijaya, L.; Alam, P.; Ashraf, M. Mitigation of sodium chloride toxicity in Solanum lycopersicum L. by supplementation of jasmonic acid and nitric oxide. J. Plant Interact. 2018, 13, 64-72. [CrossRef]

36. Zeng, C.L.; Liu, L.; Wang, B.R.; Wu, X.M.; Zhou, Y. Physiological effects of exogenous nitric oxide on Brassica juncea plants under $\mathrm{NaCl}$ stress. Biol. Plant. 2011, 55, 345-348. [CrossRef]

37. Tiwari, S.; Lata, C.; Chauhan, P.S.; Nautiyal, C.S. Pseudomonas putida attunes morphophysiological, biochemical and molecular responses in Cicer arietinum L. during drought stress and recovery. Plant Physiol. Biochem. 2016, 99, 108-117. [CrossRef] [PubMed]

38. Lv, D.W.; Zhu, G.R.; Zhu, D.; Bian, Y.W.; Liang, X.N.; Cheng, Z.W.; Deng, X.; Yan, Y.M. Proteomic and phosphoproteomic analysis reveals the response and defense mechanism in leaves of diploid wheat T. monococcum under salt stress and recovery. J. Proteomics 2016, 143, 93-105. [CrossRef] [PubMed]

C 2019 by the authors. Licensee MDPI, Basel, Switzerland. This article is an open access article distributed under the terms and conditions of the Creative Commons Attribution (CC BY) license (http://creativecommons.org/licenses/by/4.0/). 